\title{
Study on Microstructure and Properties of Surface Composition with Steel Matrix
}

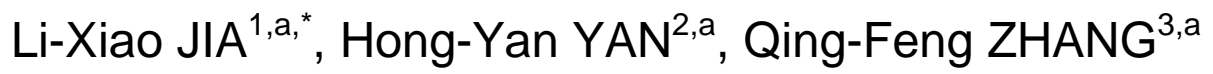 \\ ${ }^{1}$ College of Materials Science and Engineering, Luoyang Institute of Science and Technology, \\ Luoyang Henan, 471023, China \\ ajialx2001@163.com, byanhongyan@126.com, chinalyzqf@126.com \\ ${ }^{*}$ Corresponding author
}

Keywords: Casting-penetration, High-chromium Cast Iron, Microhardness, Impact Wear.

\begin{abstract}
With the traditional casting Penetration technology, high chromium cast iron composite layer has been formed on the surface of low carbon steel. The microstructure and Properties of cast Penetrating layer has been also studied. The test result has shown that the average microhardness of cast penetrating layer has been about $700 \mathrm{HV}$ and the hardness from composite layer to matrix changes smoothly. Among the three kinds of samples with different composition, the impact wear property of the sample with $40 \%$ chromium has been the best and its wear resistance has been 3.26 times of ZG230-450.
\end{abstract}

\section{Introduction}

Composite is a material which combines two or more kinds of materials into a unity and surface composite is that a composite layer is formed on the surface of matrix material. Surface composite can improve the surface properties while keeping the whole performance of matrix. Surface composites have many preparation methods and casting penetration is an efficient method. Casting penetration is used for the preparation of surface composites is initialed by an American whose name is Davis in 1913 [1]. The fundamental principle of casting penetration is pouring the metal into a mould in the special position of which a compound consists of alloy powder and bonder is brushed or a block made of alloy powder and bonder is placed in advance. In the process of pouring, the mother metal penetrates into the capillary interstice of the coating or the block and melts the alloy powder. The molten alloy powder is bond to the mother metal metallurgically and a composite layer with properties of resistance to wear, resistance to heat or resistance to corrosion and other special performance is formed on the surface of the casting after cooling. Using casting penetration technology, a casting which has higher resistance to wear and higher impact load bearing capacity can be made by choosing the mating mother metal and surface composite layer. Furthermore, casting penetration technology has the merit of simple process and lower cost. Therefore, this method is often used to prepare surface composite for the purpose of improving the properties of casting. In numerous materials, high chromium cast iron is a kind of traditional wear resistant material but has low toughness. And low carbon steel has preferable toughness but has lower wear resistance. A composite with both wear resistance and impact load bearing capacity can be prepared by combining high chromium cast iron with low carbon steel. A high chromium cast iron composite layer was prepared on the surface of low carbon steel by using casting penetration technology in this study in order to improve the surface wear resistance of casting and extend the application of casting penetration technology.

\section{Experimental Method and Details}

The whole experiment details included two steps. The first was the preparation of surface composite and the second was the detection for the microstructures and properties of surface composite. The two steps would be described in details as follows. 


\section{Preparation of Surface Composite}

The mother metal made up of ZG230-450 was smelted in a medium-frequency induction furnace which had a capacity of 50 kilogram. The molten metal was poured into the casting mould made of sodium silicate sand when the temperature reached to 1700 degree centigrade. Alloy powder the main composition of which was high chromium cast iron was used as penetrating agent while casting. A small quantity of nickel and molybdenum was added into the penetrating agent in order to improve its quenching degree. Some sodium borate was also added into the penetrating agent in order to improve its meltability. The uniform mixed alloy powder was made into mushy by alcohol resin solution and was brushed in the bottom of the mould cavity. The thickness of brushing coat was 3 millimeter. The length, width and height of the mould cavity were 100 millimeter, 60 millimeter and 20 millimeter respectively. The brushed mould must be dried in a drying oven before pouring. The two half moulds were assembled into a whole and the molten metal was poured into the mould after the assembling had been finished. A composite layer would be formed on the casting surface after cooling and solidifying.

\section{Detection for Microstructures and Properties of Surface Composite}

Samples with length and width of 15 millimeter, while with height of 10 millimeter were cut from the casting with composite layer. And then they were made into metallographic specimen along the longitudinal section according to the standard preparation method. The prepared metallographic specimen was corroded by natal solution which contains nitric acid of 4 percent in volume. The microstructure of composite layer was examined by a scanning electron microscope with type of JSM-5610LV and the combination state of composite layer with matrix was observed by a metallographic microscope with type of PMG3. The microhardness of specimen and the impact wear property were detected by a microhardness tester with type of $\mathrm{MH}-3$ and a dynamic load abrasive wear testing machine with type of MLD-3. In the course of wear examination, it was supposed that the impact number varied normally with the impact energy. Impact number was calculated based on the designed impact energy and then impact time was calculated based on impact frequency and impact number. Finally, abrasive loss in per second was calculated according to the difference in weight before and after per wear experiment. The weight of samples was measured by a balance with a accuracy of 0.0001 gram.

\section{Experimental Result and Discussion}

\section{Observation of Microstructure and Combination status of Surface Layer with Matrix}

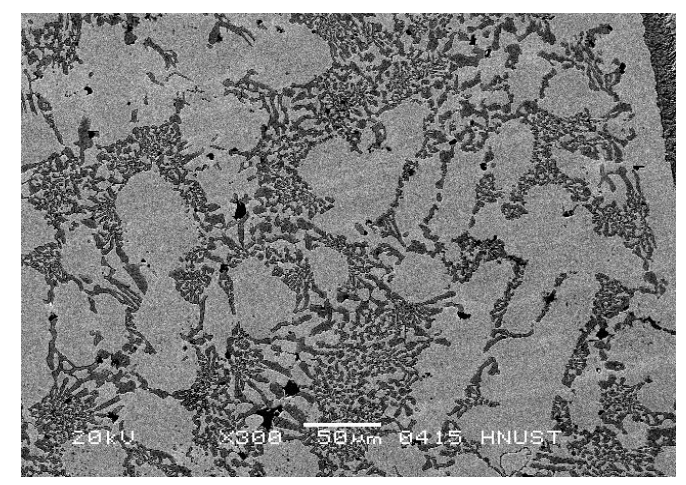

Fig.1 microstructure of the surface layer

Figure 1 and 2 showed the microstructures of composite layer and their combination status with matrix respectively. From figure 1, it could be shown that iron carbides in chrysanthemum shape were distributed on the austenite matrix in the microstructure of composite layer at cast condition. The analysis of x-ray diffraction indicated that the iron carbide in composite layer was mainly in form of 
$\mathrm{M}_{7} \mathrm{C}_{3}$. This microstructure was typical microstructure of high chromium cast iron at cast condition. In figure 2, the darker part at left hand was matrix and the brighter part at right hand was composite layer. There was an interlocking layer between the matrix and the surface layer. It was formed by counter-diffusion in matrix and surface layer. It was also seen from the figure 2 that high chromium cast iron added in alloy powder had been molten and formed new phase after cooling. This phenomenon indicated that metallurgical bonding was formed in matrix and surface composite layer.

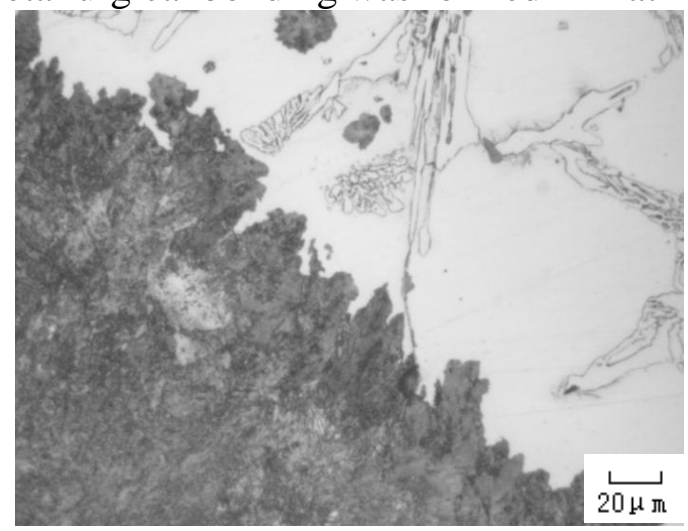

Fig. 2 Interface between matrix and surface layer

\section{Properties of Surface Composite Layer}

Microhardness of Surface Composite Layer. Figure 3 showed the microhardness distribution of surface composite examined by microhardness tester with type of MH-3 in the direction perpendicular to the sample surface. From the figure, it was indicated that the average microhardness value of composite layer was about $700 \mathrm{HV}$ while the same value of matrix was about $250 \mathrm{HV}$. The reason for that the composite layer was harder than the matrix obviously was that the alloy elements were molten by the liquid matrix metal and chromic carbides with type of $\mathrm{M}_{7} \mathrm{C}_{3}$ were formed during casting. And chromic carbides were a very hard phase. Meanwhile, figure 3 indicated that there was a gradual hardness gradient from composite layer to matrix. It was because that there was a transition zone between composite layer and matrix. In the transition zone, the microstructure varied gradually from high chromium cast iron to low carbon steel. This gradual hardness gradient was benefit to improve the wear resistance of the surface composite [2].

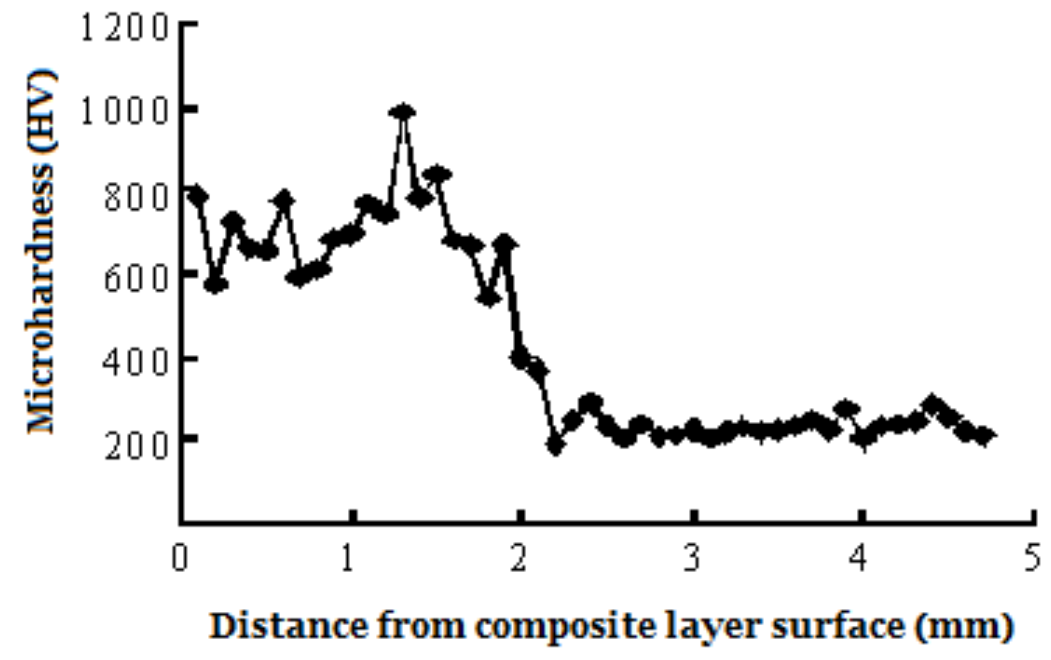

Fig.3 Microhardness distribution of the surface composite

Impact Wear Property of Surface Composite. In order to investigate the wear impact properties of the surface composite, three kinds of samples with different penetration agents were cut from the casting. The contents of $\mathrm{Ni}$ and Mo in the samples were 1.5 percent and 0.5 percent by volume 
respectively and the contents of high chromium cast iron in the samples were 20 percent, 40 percent and 60 percent respectively. The variation trend of average wear rate with the change of chromium iron content was shown in figure 4. It was indicated that the mean wear rate of the three samples increased firstly and then decreased with the increase of chromium iron content. The wear rate was highest when chromium iron content was 40 percent and its value was lower than the other two samples evidently. It was because that wear resistance of the composite layer was mainly depended on the form and the amount of the carbide. There had three principle kinds of chromium carbide which forms were $\mathrm{M}_{3} \mathrm{C}, \mathrm{M}_{23} \mathrm{C}_{6}$ and $\mathrm{M}_{7} \mathrm{C}_{3}$ in the microstructure of high chromium cast iron. In the three carbides, the hardness of $\mathrm{M}_{7} \mathrm{C}_{3}$ was the highest and therefore, its wear resistance was the best too. The amount of chromium carbide in the composite layer could be calculated according to the formula as $K=12.33 C+0.55 C r-15.2$ [3]. In the formula, $K$ is the amount of chromium carbide in composite layer, $C$ is the content of carbon in mass and $C r$ is the content of $\mathrm{Cr}$ in mass. The amounts of chromium carbides in the surface layer of samples calculated depending on the above formula were about 10 percent, 30 percent and 55 percent respectively. Reference literaure [4] indicated that the wear resistance of high chromium cast iron with carbide of 30 percent was higher than the others. Furthmore, carbides were easily to separate from the matrix because of their weaken combination with the matrix. Therefore, wear resistance of the sample with 40 percent chromium content was the best in the three samples.

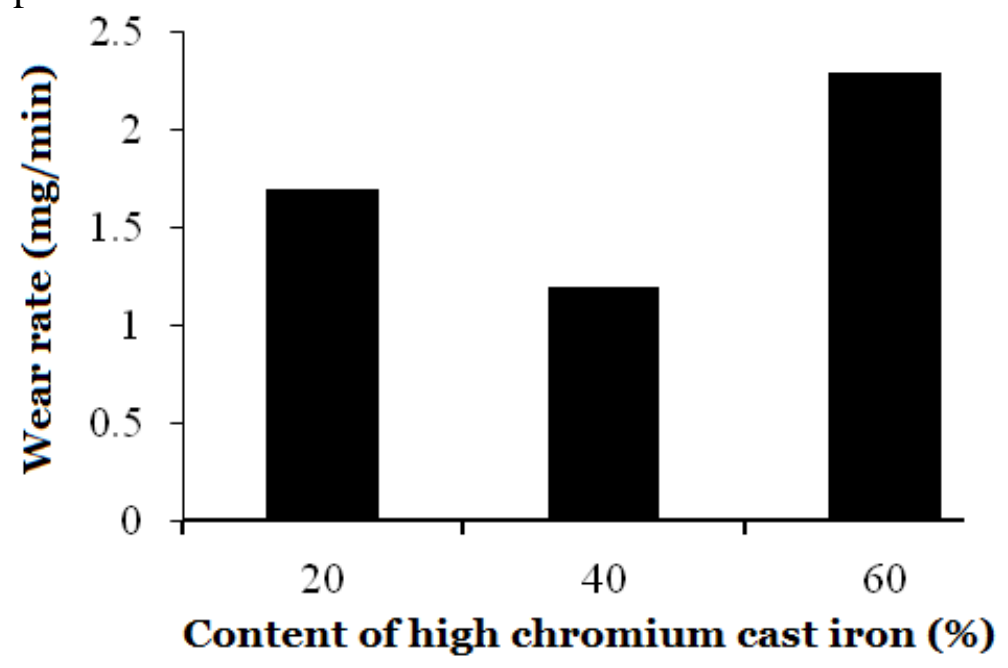

Fig.4 Comparison among the three surface composites

Table 1 showed the relationship between wear rate variation of the sample with best wear resistance and impact energy. From the table, it was indicated that wear rate of the surface composite increased firstly and then decreased but that of the ZG230-450 sample decreased invariably with the increase of the impact energy. Wear rate of the surface composite sample was obviously lower than that of ZG230-450 sample when the impact energy was lower than 2 joules. But wear rate of the surface composite sample was higher than that of ZG230-450 sample when the impact energy was greater than 2 joules. Calculation showed that the wear rate of ZG230-450 was 3.26 times of that for surface composite. The reason for this phenomenon was that wear resistance the materials were mainly depended on their hardness under the condition of relatively low energy impact. The higher the hardness, the better the wear resistance. The $\mathrm{M}_{7} \mathrm{C}_{3}$ carbides with very high hardness made the surface composite samples very hard so they had good wear resistance. Meanwhile, the austenite in matrix of the surface composite could change into martensite induced by stress during wearing. Consequently, pressure stress would be generated in wearing surface layer and this stress would prevent the formation and expansion of cracks [5]. If the impact energy was relatively higher, the hard and brittle carbide in composite layer would be easily to take off from the matrix because of the impact power. Therefore, the wear rate of surface composite at condition of high energy impact was higher than that at condition of low energy impact, on the contrary. 
Tab.1 Relationship between wear rate of two samples and impact energy

\begin{tabular}{|c|c|c|}
\hline $\begin{array}{c}\text { Impact energy } \\
(\mathrm{J})\end{array}$ & $\begin{array}{c}\text { Wear rate of surface composite } \\
(\mathrm{mg} / \mathrm{min})\end{array}$ & $\begin{array}{c}\text { Wear rate of ZG230-450 } \\
(\mathrm{mg} / \mathrm{min})\end{array}$ \\
\hline 0.5 & 1.975 & 1.575 \\
\hline 1 & 0.639 & 3.628 \\
\hline 1.5 & 0.361 & 1.52 \\
\hline 2 & 0.756 & 0.528 \\
\hline 2.5 & 0.851 & 0.358 \\
\hline 3 & 1.622 & 0.222 \\
\hline 3.5 & 6.025 & 0.175 \\
\hline 4 & 1.975 & 1.575 \\
\hline
\end{tabular}

\section{Conclusions}

Composite layer with microstructure of high chromium cast iron was formed on the low carbon steel casting by classical casting penetration process. The hardness of composite layer was obviously higher than that of matrix. Wear resistance of three kinds of samples with different high chromium cast iron content was compared and it was found that the sample with high chromium cast iron content of 40 percent possessed the lowest wear rate. Under the applied test condition, the wear rate of ZG230-450 was 3.26 times of that for surface composite when impact energy was lower than 2 joules.

\section{Acknowledgement}

This research was financially supported by the Key Project of Science and Technology Department of Henan Province of China( 142102210121).

\section{References}

[1] J.X. Yang, Research on surface composite reinforced by carbide particles prepared by means of casting penetration, Master Disertation. Shandong Agricultural University, Taian, 1999.

[2] B. Xu., J.X. Yang, C.M. Feng, Research on high chromium casting penetration layer reinforced by WC particles on surface of cast iron, Hot Machining Technology, 24(1998) 10-11.

[3] B.M. Zhang, Cast handbook(volume 1), Cast Iron, China Machine Press, Beijing, 2011.

[4] J.M. Li. Antiwear and antifriction materials. China Machine Press, Beijing, 1985.

[5] B.J. Zhang, X.A. Qiao, J.A, W.H. Liu, Production application of high chromium cast iron with austenite matrix, Research Studies on Foundry Equipment,6(2001) 28-29. 